ENCYCLOPEDDIE Encyclopédie berbère

BERBERE

32 | 2010

32 | Mgild - Mzab

Miknaça / Miknasa (*Imeknasen)

\title{
A. Khelifa
}

\section{OpenEdition}

Journals

Édition électronique

URL : https://journals.openedition.org/encyclopedieberbere/603

DOI : 10.4000/encyclopedieberbere.603

ISSN : 2262-7197

\section{Éditeur}

Peeters Publishers

\section{Édition imprimée}

Date de publication : 31 décembre 2010

Pagination : 5019-5021

ISBN : 978-90-429-2369-0

ISSN : 1015-7344

\section{Référence électronique}

A. Khelifa, « Miknaça / Miknasa (*/meknasen) », Encyclopédie berbère [En ligne], 32 | 2010, document

M115, mis en ligne le 06 novembre 2020, consulté le 17 février 2022. URL : http://

journals.openedition.org/encyclopedieberbere/603 ; DOI : https://doi.org/10.4000/ encyclopedieberbere.603

Ce document a été généré automatiquement le 17 février 2022.

(c) Tous droits réservés 


\section{Miknaça / Miknasa (*Imeknasen)}

\section{A. Khelifa}

1 Grande tribu appartenant à la confédération des Zenata*. Ils descendent de Warstif ibn Yahia Ibn Dari. C'est pour cette raison qu'on les appelle quelquefois Wartasif-Miknasa et que les différentes tribus qui en sont issues sont confondues dans le générique Miknasa. Ils sont frères des Awkna (Makkan) et des Wartanadj. Ibn Khaldun nous apprend que les enfants de Wartsif, fils de Yahia et frère de Djana et de Semgan forment trois tribus : les Miknasa, les Ournadja et les Augna (Megna). Ibn Khaldun, cite également les Banu Hawwat, Les Banu Kansara, Les Banu Sulat (Muwallat), Les Banu Wanifa (Wartifa) les Banu Warflas, les Banu Waridûs (Wartadûs) et les Banu Wariflita (Taflit), les Harat, les Ounifa. Cette tribu semble s'être déplacée d'est en ouest avant les autres tribus zénètes. Les diverses branches de la tribu de Wartsif se fondirent dans celle des Miknasa qui occupèrent les rives de la Moulouya depuis la source jusqu'à l'embouchure. Ces tribus reconnaissaient le commandement de la famille Abou Izzoul ou Medjdoul, fils de Tafris, fils de Feradis, fils de Ounif, fils de Miknas.

2 Une grande partie des Miknassiens traversa le détroit lors de la conquête de l'Espagne et s'y fixèrent. Ils devinrent très nombreux et puissants. En $151 \mathrm{H} / 768$, une partie d'entre eux prirent cause pour Chakia Ibn Abd el-Ouahed qui se souleva contre Abderrahmane el-Dakhil.

Messala Ibn Habbous Ibn Menazel, grand chef miknassien prit, au Xe siècle, le parti de la dynastie fatimide régnant à Mahdia, Il fut proche de 'Obeïd Allah el-Mahdi et devint un de ses principaux généraux. Il obtint le gouvernement de Tihert et soumis tout le Maghreb central ainsi que Fès et Sijilmassa. A sa mort, le commandement passa à son frère Isliten Ibn Habbous. Hamid, fils de Isliten, changea d'alliance et proclama la souveraineté de Abd el-Rahmane El-Nacir souverain d'Al-Andalus. Plus tard il passa en Espagne et eut d'importantes fonctions sous El-Nacir et sous son fils El-Hakem. Il commanda à Tlemcen au nom de cette dynastie. Isel, fils de Hamid eut le gouvernement de Sijilmassa pour le compte des Omeyyades de Cordoue.

4 El-Bekri nous apprend qu'au nord de la ville de Tihert*, il y avait des Miknasa aux côtés des Matmata et des Zenata. Plus loin, il parle de Miknasa Ibadites qui sont au nord de la ville de Tehouda près de Biskra. Sur la route de Ténès à Tihert, El-Bekri nous apprend 
qu'on passe par Tadjemout, par le défilé des Meknasa. Il ajoute que pour aller de Oujda à Fès, il faut se rendre à Za, puis à Taberida, puis chez les Miknasa qui habitent des cabanes construites de broussailles. Il signale dans l'itinéraire qui va de Fès à Kairouan en passant par le Sebou, qu'on arrive à une localité appelée Khandaq el-Foul (la ravine aux fèves) qui appartient aux Miknasa ainsi que le défilé de Taza. Puis on arrive à une rivière salée, Ouadi Ouarogguin qui coule dans le territoire des Miknasa. En allant vers la montagne de l'Aurès, « après avoir atteint le Nahr el-Ghaba » sur une étendue de sept journées de marche, on trouvait « un grand nombre de places fortes appartenant aux Hawwara* et aux Miknasa qui professent les doctrines hérétiques de la secte ibadite ». Sijilmassa fut fondée en 757/58 par les miknassiens Banu Wasul-Banu Midrar* et ainsi la première unité politique car la tribu vivait le long de la Moulouya depuis la source jusqu'à l'embouchure. L'emplacement de la ville correspondait à une volonté de contrôler le commerce de l'or. La dynastie disparut avec la prise de la ville par les Maghrawa* en 976. En fait cette tribu occupe des lieux allant de Tehuda à Meknès en passant par les monts de l'Aurès*, Baghaï, Ngaous, L'Ouarsenis*, Al-Ghuzza, Tlemcen, le col de Taza, Djebel Zerhoun. Le second royaume commandé par les Banu Afuya s'étendait autour du Tasûl.

El-Idrisi, lui, situe les Miknasa avec le pays de Sijilmassa, le Dra', Tadla, Qal'at Mahdi Ibn Tawala, Fès, Meknès, Sala, sur l'Atlantique, Tlemcen, Tittan-u-Qara, Sefrou, Maghila, Aqarcif (Guercif) Karanita, Oujda, Mélilia, Oran, Tihert, Achir. Il attribue la ville de Meknès à Miknas, le Berbère, depuis le moment où il se fixa dans la ville avec ses enfants «assignant à ces derniers un emplacement à mettre en valeur ». Il cite deux fractions de cette tribu, les Banu Moussa et les Banu Saïd.

$6 \quad \mathrm{Au} \mathrm{XIV}{ }^{e}$ siècle, des restes de cette grande tribu vivaient encore dans les montagnes qui bordent Taza, leur ancien territoire. Ils prêtèrent serment aux Mérinides*.

\section{BIBLIOGRAPHIE}

Anonyme du Kitab el-Istibçar, L'Afrique septentrionale au XII siècle de notre ère, trad. E. FAGNAN, Recueil de Constantine, 1899.

EL BEKRI, Description de l'Afrique, trad. De Slane, Paris, 1965.

EL IDRISI,. Le Maghrib au XII siècle, trad. Hadj Sadok, Alger, 1983.

IBN HAWQAL, Configuration de la terre, introduction et trad. par Kramers et Wiet, Beyrouth, Maisonneuve, Larose, 2 volumes.

IBN KHALDUN A., Histoire des Berbères et des dynasties musulmanes de l'Afrique septentrionale, trad. De Slane, 4 volumes, Paris, 1978.

INDEX

Mots-clés : Histoire, Moyen Âge, Tribu 